\title{
What Factors Affect Changes in Body Composition and Swallowing Function in Patients Hospitalized for Oral Cancer Surgery?
}

This article was published in the following Dove Press journal:

Clinical Interventions in Aging

\section{Yuko Kagifuku' \\ Haruka Tohara (D) \\ Yoko Wakasugi \\ Chiaki Susa' \\ Ayako Nakane' \\ Mizue Toyoshima ${ }^{2}$ \\ Koichi Nakakuki ${ }^{3}$ \\ Yuji Kabasawa (iD ${ }^{4}$ \\ Hiroyuki Harada ${ }^{5}$ \\ Shunsuke Minakuchi (iD) \\ 'Department of Gerontology and Gerodontology, Division of \\ Gerodontology and Oral Rehabilitation, Graduate School of Medical and Dental Sciences, Tokyo Medical and Dental University, Tokyo, Japan; ${ }^{2}$ Section of Nutrition Management, Tokyo Medical and Dental University Dental Hospital, \\ Tokyo, Japan; ${ }^{3}$ Department of Maxillofacial Surgery, Division of Maxillofacial and Neck Reconstruction, Graduate School of Medical and Dental Sciences, Tokyo Medical and Dental University, Tokyo, Japan; ${ }^{4}$ Department of Oral Care for Systemic Health Support, Graduate School of Health Care Sciences, Tokyo Medical and Dental University, Tokyo, Japan; ${ }^{5}$ Department of Oral and Maxillofacial Surgery, Oral Restitution, Division of Oral Health Sciences, Graduate School of Medical and Dental Sciences, Tokyo Medical and Dental University, Tokyo, Japan}

Correspondence: Haruka Tohara Department of Gerontology and Gerodontology, Division of

Gerodontology and Oral Rehabilitation Graduate School of Medical and Dental Sciences, Tokyo Medical and Dental University, 1-5-45 Yushima, Bunkyo-ku,

Tokyo II 3-85I0, Japan

$\mathrm{Tel} / \mathrm{Fax}+8 \mathrm{l}-3-5803-5559$

Email haruka-t@rd5.so-net.ne.jp
Purpose: There are few studies about sarcopenia before and after surgery for oral cancer. Therefore, we examined body composition during hospitalization and factors affecting weight loss, skeletal muscle mass index (SMI) reduction, and swallowing function at discharge in this patient group.

Patients and Methods: A prospective survey was conducted at Tokyo Medical and Dental University Dental Hospital for patients who underwent primary surgery for oral cancer and reconstruction using free flaps. We compared body weight, SMI, grip strength, and walking speed at admission and discharge. We also examined factors affecting weight loss and SMI reduction and the functional oral intake scale (FOIS) score at discharge.

Results: There were 26 patients that we could survey during the period. As a result of Wilcoxon's signed-rank test, body weight, SMI, and grip strength were significantly reduced during hospitalization, but no reduction was noted for sarcopenia. As a result of multiple regression analysis, postoperative chemoradiotherapy was a risk factor for weight loss, reduced SMI, and low FOIS score at discharge.

Conclusion: Postoperative chemoradiotherapy is a risk factor for weight loss, muscle mass loss, and dysphagia at discharge, and chemoradiotherapy may affect rather than an invasion of surgery. After surgery, besides follow-ups for cancer, oral cancer patients should be followed up to assess dysphagia, undernutrition, and sarcopenia.

Keywords: sarcopenia, chemoradiotherapy, dysphagia, head and neck cancer

\section{Introduction}

Although sarcopenia has recently attracted attention in fields such as gerontology and perioperative care, few studies have examined changes in body composition of head and neck cancer patients. Sarcopenia is defined as an age-related loss of skeletal muscle mass and strength. ${ }^{1,2}$ The increased use of the Enhanced Recovery After Surgery protocol in gastroenterology has led to the development of postoperative recovery programs that enforce early postoperative resumption of oral intake and seek to shorten postoperative hospital stays. ${ }^{3,4}$ Numerous studies have found that sarcopenia prior to surgery for gastrointestinal cancer is a risk factor for postoperative complications, while other studies have described the importance of preoperative nutritional intervention. $^{5-7}$ In contrast, sarcopenia is not routinely assessed in head and neck cancer patients. ${ }^{8}$ Despite studies showing that preoperative sarcopenia is a risk factor for postoperative complications, ${ }^{9,10}$ no study has examined changes in body composition among patients hospitalized for head and neck cancer surgery. 
Another problem with head and neck cancer is the difficulty patients experience in resuming early postoperative oral intake because of treatment affecting their swallowing organs. ${ }^{11}$ While the length of hospital stay following surgery for other gastrointestinal cancers is roughly 12 days, ${ }^{12,13}$ the hospital stay following surgery for oral cancer can extend to about 23 days. ${ }^{14}$ Despite the wide variety of methods employed in postoperative rehabilitation for dysphagia, some patients may still require tube feeding whereas other patients may be restricted to only puree at discharge. Furthermore, some patients experience a reduction in body weight even during hospitalization. Sarcopenia is a systemic process that also affects the muscles dedicated to swallowing. ${ }^{15,16}$ Although chemoradiotherapy affects postoperative weight reduction and swallowing function, ${ }^{17}$ it is unknown whether pre- and post-surgical changes in muscle mass affect swallowing function.

In the present study, we examined the changes in body composition and sarcopenia before and after surgery in oral cancer patients, factors that affected reduction in body weight and muscle mass, and factors that affected swallowing function at discharge.

\section{Materials and Methods}

This prospective survey was conducted at the Tokyo Medical and Dental University Dental Hospital. Patients who underwent primary tumor resection for oral cancer and reconstruction using free flaps for oral defects between January and September 2016 were eligible for this study. Because we intended to examine how hospitalization for surgery affects body composition, we excluded patients who had previously undergone chemoradiotherapy and patients with cancer in other organs.

We examined body weight, body mass index (BMI), skeletal muscle mass index (SMI), grip strength, and gait speed at admission and discharge. We measured appendicular muscle mass by bioimpedance analysis using In Body S10 (In Body Japan Inc., Tokyo, Japan). During measurements, subjects were instructed to rest in a supine position. The acquired appendicular muscle mass was divided by the square of the subject's height and used as SMI. Grip strength was measured with a digital dynamometer (TTM, Inc., Tokyo, Japan); we calculated the mean of 3 measurements taken with the patient's dominant hand or the hand on the opposite side of where the free flap was used. Gait speed was measured over the middle 4 meters of an 8-meter walk; we calculated the mean value for a round trip. Sarcopenia was diagnosed in accordance with the Asian Working
Group for Sarcopenia (AWGS) algorithm. ${ }^{2}$ The gait speed cutoff value was $0.8 \mathrm{~m} / \mathrm{s}$, the handgrip strength cutoff values were $26 \mathrm{~kg}$ for men and $18 \mathrm{~kg}$ for women, and the SMI cutoff values were $7.0 \mathrm{~kg} / \mathrm{m}^{2}$ for men and $5.7 \mathrm{~kg} / \mathrm{m}^{2}$ for women, according to the values suggested by AWGS.

We also evaluated preoperative serum albumin (Alb) levels, tumor site, and tumor stage and assessed whether the patients received radiotherapy, chemotherapy, or both. Furthermore, we investigated the postoperative length of hospital stay and the functional oral intake scale (FOIS) score at discharge. FOIS was recorded by reviewing the patient's chart.

Body weight, SMI, grip strength, and gait speed at admission and discharge were compared using the Wilcoxon signed-rank test. A multiple regression analysis was performed using forced-entry method to examine factors affecting body weight and SMI reduction during hospitalization and the FOIS score at discharge. Body weight and SMI reduction were set as dependent variables, whereas age, sex, preoperative BMI, and postoperative chemoradiotherapy were set as independent variables. The FOIS score was set as the dependent variable, whereas age, sex, SMI reduction, and post-operative chemoradiotherapy were set as the independent variables.

For our analysis, postoperative chemoradiotherapy was defined as radiotherapy alone, chemotherapy alone, or the combination of both. A correlation coefficient matrix table was prepared in advance, and the analysis was performed using Spearman's rank correlation coefficient. Statistical analysis was performed using SPSS version 22.0 (IBM, IL, USA), while the statistical power was analyzed using G*Power 3.1 software (Kiel University, Kiel, Germany).

This study was approved by the Ethics Committee of the School of Dentistry of Tokyo Medical and Dental University (1272). The participants' consent was written informed consent. The study was conducted according to the tenets of the Declaration of Helsinki.

\section{Results \\ Subjects}

A total of 47 patients with oral cancer underwent reconstruction using free flaps during the study period. Of these, we excluded 9 patients who had previously undergone chemoradiotherapy, 3 with malignancies in other organs, 8 from whom we could not obtain consent, and 1 who could not be examined prior to surgery. Table 1 shows the characteristics of the 26 subjects ultimately included in the present study. 
Table I Subjects' Characteristics $(n=26)$

\begin{tabular}{|c|c|}
\hline \multicolumn{2}{|l|}{ Characteristics } \\
\hline Men (\%) & $\mathrm{n}=15(58)$ \\
\hline Age (years), median (IQR) & $66.5(45-8 I)$ \\
\hline Weight (kg), median (IQR) & $59.3(42.7-87.4)$ \\
\hline BMI $\left(\mathrm{kg} / \mathrm{m}^{2}\right)$, median (IQR) & $23.2(17.7-32.5)$ \\
\hline Alb (g/dl), median (IQR) & $4.4(3.9-4.9)$ \\
\hline Tumor & \\
\hline Mandible or mandibular gingiva & 14 \\
\hline Tongue & 9 \\
\hline Oral floor & 2 \\
\hline Buccal mucosa & 1 \\
\hline T stage & \\
\hline TI & 2 \\
\hline $\mathrm{T} 2$ & 11 \\
\hline T3 & 4 \\
\hline T4 & 9 \\
\hline Postoperative chemoradiotherapy & \\
\hline Radiotherapy & I \\
\hline Chemotherapy & I \\
\hline Chemoradiotherapy & 3 \\
\hline $\begin{array}{l}\text { Length of hospital stay after surgery (days), } \\
\text { median (IQR) }\end{array}$ & $32(22-13 \mid)$ \\
\hline FOIS at discharge & \\
\hline Level I & 1 \\
\hline 2 & 0 \\
\hline 3 & 0 \\
\hline 4 & 5 \\
\hline 5 & 17 \\
\hline 6 & 1 \\
\hline 7 & 2 \\
\hline
\end{tabular}

Abbreviations: IQR, interquartile range; BMI, body mass index; Alb, albumin; FOIS, functional oral intake scale.

\section{Measurement Results}

Body weight, SMI, and grip strength all significantly decreased at discharge $\left(P<0.001^{*} \alpha=0.05\right)$, while no significant change was observed in gait speed $(P=0.889$, $\alpha=0.05$ ) (Table 2). The mean reduction in body weight was $4.0 \mathrm{~kg}$, and the mean percentage of body weight at discharge compared with body weight at admission was $93.5 \%$. The mean reduction in SMI was $0.5 \mathrm{~kg} / \mathrm{m}^{2}$, and the mean percentage of SMI at discharge compared with SMI at admission was $93.5 \%$. The mean reduction in grip strength was $3.5 \mathrm{~kg}$, and the mean percentage of grip strength at discharge compared with grip strength at admission was $89.4 \%$. According to the post-facto analysis, the statistical power of comparisons of body weight, SMI, and grip strength at admission and discharge was $0.99,0.95$, and
Table 2 Comparisons of Body Weight, SMI, Grip Strength, and Gait Speed at Admission and Discharge

\begin{tabular}{|l|l|l|l|}
\hline Characteristics & $\begin{array}{l}\text { Admission } \\
\text { (Median) }\end{array}$ & $\begin{array}{l}\text { Discharge } \\
\text { (Median) }\end{array}$ & $P$ - value \\
\hline Body weight, kg & 59.3 & 54.7 & $\begin{array}{l}<0.00 I^{*} \\
\text { ES }=-0.87\end{array}$ \\
\hline SMl, kg/m² & 7.77 & 7.41 & $\begin{array}{l}<0.00 I^{*} \\
\text { ES }=-0.76\end{array}$ \\
\hline Grip strength, kg & 33.3 & 29.2 & $\begin{array}{l}<0.00 I^{*} \\
\text { ES }=-0.78\end{array}$ \\
\hline Gait speed, $\mathrm{m} / \mathrm{s}$ & 1.17 & 1.25 & $\begin{array}{l}0.889 \\
\text { ES }=-0.03\end{array}$ \\
\hline
\end{tabular}

Note: $* P<0.001$.

Abbreviations: SMI, skeletal muscle mass index; ES, effect size.

0.95 , respectively (Table 3 ). Sarcopenia was present in 1 patient at admission and in 2 patients at discharge. The patient with sarcopenia at admission also had sarcopenia at discharge; thus, only 1 hospitalized patient was newly diagnosed with sarcopenia.

The correlation between the variables were confirmed in Table 4, and a high correlation coefficient was noted only between body weight reduction and SMI reduction ( $\mathrm{r}=0.898)$. The other correlation coefficients were $\mathrm{r}<0.8$. The results of the multiple regression analysis are shown in Table 5. Preoperative BMI and postoperative chemoradiotherapy were factors associated with body weight reduction during hospitalization. The adjusted coefficient of determination $\left(\mathrm{R}^{2}\right)$ was 0.398 . The standardized regression coefficients for preoperative BMI and postoperative chemoradiotherapy were $-0.466(P<0.001)$ and $0.515(P<0.001)$, respectively. Sex, preoperative BMI, and postoperative chemoradiotherapy were factors associated with SMI reduction during hospitalization. The $\mathrm{R}^{2}$ was 0.577 . The standardized regression coefficients for sex, preoperative BMI, and postoperative chemoradiotherapy were $0.351(P<0.05), 0.543$ $(P<0.001)$, and $-0.358(P<0.001)$, respectively. Postoperative chemoradiotherapy was associated with the

Table 3 Wilcoxon Signed-Rank Test Analysis of the Variables

\begin{tabular}{|l|l|l|l|}
\hline Variables & ES & $\begin{array}{l}\text { Total Sample } \\
\text { Size }\end{array}$ & $\begin{array}{l}\text { Power } \\
(I-\beta)\end{array}$ \\
\hline Body weight & 0.87 & 26 & 0.99 \\
SMI decline & -0.76 & 26 & 0.95 \\
Grip strength decline & -0.78 & 25 & 0.95 \\
Gait speed & -0.03 & 26 & 0.05 \\
\hline
\end{tabular}

Abbreviations: SMI, skeletal muscle mass index; ES, effect size. 
Table 4 Correlation Matrix Table of Parameters

\begin{tabular}{|c|c|c|c|c|c|c|c|c|}
\hline Parameters & $\begin{array}{l}\text { Correlation } \\
\text { Coefficient/ } \\
\text { P-values }\end{array}$ & Age & Sex & $\begin{array}{l}\text { Preoperative } \\
\text { BMI }\end{array}$ & $\begin{array}{l}\text { Postoperative } \\
\text { Chemoradiotherapy }\end{array}$ & $\begin{array}{l}\text { Weight } \\
\text { Loss }\end{array}$ & $\begin{array}{l}\text { SMI } \\
\text { Loss }\end{array}$ & $\begin{array}{l}\text { FOIS at } \\
\text { Discharge }\end{array}$ \\
\hline Age & $\begin{array}{l}r \\
P\end{array}$ & 1.000 & $\begin{array}{l}-0.005 \\
0.980\end{array}$ & $\begin{array}{l}0.239 \\
0.240\end{array}$ & $\begin{array}{l}0.163 \\
0.427\end{array}$ & $\begin{array}{l}-0.110 \\
0.593\end{array}$ & $\begin{array}{l}0.059 \\
0.776\end{array}$ & $\begin{array}{l}0.004 \\
0.984\end{array}$ \\
\hline Sex & $\begin{array}{l}r \\
P\end{array}$ & & 1.000 & $\begin{array}{l}0.358 \\
0.072\end{array}$ & $\begin{array}{l}-0.023 \\
0.912\end{array}$ & $\begin{array}{l}-0.301 \\
0.135\end{array}$ & $\begin{array}{l}0.555^{* *} \\
0.003\end{array}$ & $\begin{array}{l}-0.178 \\
0.384\end{array}$ \\
\hline Preoperative BMI & $\begin{array}{l}r \\
p\end{array}$ & & & 1.000 & $\begin{array}{l}0.124 \\
0.547\end{array}$ & $\begin{array}{l}-0.492^{*} \\
0.011\end{array}$ & $\begin{array}{l}0.589 * * \\
0.002\end{array}$ & $\begin{array}{l}0.216 \\
0.289\end{array}$ \\
\hline $\begin{array}{l}\text { Postoperative } \\
\text { chemoradiotherapy }\end{array}$ & $\begin{array}{l}r \\
p\end{array}$ & & & & 1.000 & $\begin{array}{l}0.345 \\
0.084\end{array}$ & $\begin{array}{l}-0.228 \\
0.263\end{array}$ & $\begin{array}{l}0.608 * * \\
0.001\end{array}$ \\
\hline Weight loss & $\begin{array}{l}r \\
P\end{array}$ & & & & & 1.000 & $\begin{array}{l}-0.898^{* *} \\
0.000\end{array}$ & $\begin{array}{l}0.375 \\
0.059\end{array}$ \\
\hline SMI loss & $\begin{array}{l}r \\
P\end{array}$ & & & & & & 1.000 & $\begin{array}{l}-0.229 \\
0.260\end{array}$ \\
\hline FOIS at discharge & $\begin{array}{l}r \\
P\end{array}$ & & & & & & & 1.000 \\
\hline
\end{tabular}

Note: $* P<0.05 ; * * P<0.01$.

Abbreviations: BMI, body mass index; SMI, skeletal muscle mass index; FOIS, functional oral intake scale.

Table 5 Multiple Regression Analysis Values

\begin{tabular}{|c|c|c|c|c|c|c|c|c|c|}
\hline $\begin{array}{l}\text { Dependent } \\
\text { Variable }\end{array}$ & Independent Variable & $\begin{array}{l}\text { Standardized } \\
\text { Partial Regression } \\
\text { Coefficient }\end{array}$ & $P$-value & \multicolumn{2}{|l|}{$95 \% \mathrm{Cl}$} & $\mathbf{R}$ & $\mathbf{R}^{2}$ & $\begin{array}{l}\text { Adjusted } \\
\mathbf{R}^{2}\end{array}$ & $\mathbf{f}^{2}$ \\
\hline Weight loss & $\begin{array}{l}\text { Age } \\
\text { Sex } \\
\text { Perioperative BMI } \\
\text { Postoperative } \\
\text { chemoradiotherapy }\end{array}$ & $\begin{array}{l}-0.179 \\
-0.104 \\
-0.466 \\
0.515\end{array}$ & $\begin{array}{l}0.268 \\
0.534 \\
0.010 \\
0.004\end{array}$ & $\begin{array}{l}-0.114 \\
-1.850 \\
-0.473 \\
0.968\end{array}$ & $\begin{array}{l}0.033 \\
0.987 \\
-0.072 \\
4.391\end{array}$ & 0.703 & 0.494 & 0.398 & 0.977 \\
\hline SMI loss & $\begin{array}{l}\text { Age } \\
\text { Sex } \\
\text { Perioperative BMI } \\
\text { Postoperative } \\
\text { chemoradiotherapy }\end{array}$ & $\begin{array}{l}0.087 \\
0.351 \\
0.543 \\
-0.358\end{array}$ & $\begin{array}{l}0.518 \\
0.019 \\
0.001 \\
0.013\end{array}$ & $\begin{array}{l}-0.059 \\
0.375 \\
0.207 \\
-4.579\end{array}$ & $\begin{array}{l}0.113 \\
3.677 \\
0.674 \\
-0.595\end{array}$ & 0.803 & 0.645 & 0.577 & 1.815 \\
\hline FOIS at discharge & $\begin{array}{l}\text { Age } \\
\text { Sex } \\
\text { SMI loss } \\
\text { Postoperative } \\
\text { chemoradiotherapy }\end{array}$ & $\begin{array}{l}-0.047 \\
-0.270 \\
0.301 \\
0.666\end{array}$ & $\begin{array}{l}0.789 \\
0.202 \\
0.179 \\
0.002\end{array}$ & $\begin{array}{l}-0.048 \\
-1.496 \\
-0.056 \\
0.759\end{array}$ & $\begin{array}{l}0.037 \\
0.335 \\
0.280 \\
2.833\end{array}$ & 0.629 & 0.395 & 0.280 & 0.654 \\
\hline
\end{tabular}

Abbreviations: $\mathrm{Cl}$, confidence interval; BMI, body mass index; SMI, skeletal muscle mass index; FOIS, functional oral intake scale.

FOIS score at discharge. The $\mathrm{R}^{2}$ was 0.280 . The standardized regression coefficient for postoperative chemoradiotherapy was $0.666(P<0.05)$. According to the post-facto analysis, the statistical power of tests for body weight reduction, SMI reduction, and FOIS score at discharge, as the dependent variables, were $0.97,1.00$, and 0.85 , respectively (Table 6).

\section{Discussion}

Our results revealed two notable findings. First, there were significant reductions in body weight, muscle mass, and grip strength during hospitalization. However, these reductions were not severe enough to lead to sarcopenia. Second, postchemoradiotherapy was associated with reduced body 
Table 6 Statistical Power Analysis of Discharge Variables

\begin{tabular}{|c|c|c|c|}
\hline Variables & $\operatorname{ES}\left(f^{2}\right)$ & Total Sample Size & Power $(1-\beta)$ \\
\hline Weight loss & 0.98 & 26 & 0.97 \\
\hline SMI loss & 1.82 & 26 & 1.00 \\
\hline FOIS at discharge & 0.65 & 26 & 0.85 \\
\hline
\end{tabular}

Abbreviations: ES, effect size; SMI, skeletal muscle mass index; FOIS, functional oral intake scale.

weight and SMI during hospitalization and with the FOIS score at discharge.

Body weight, SMI, and grip strength all significantly decreased during hospitalization. A previous study found that among patients who underwent reconstruction for tongue cancer, body weight at discharge was $93.5 \%$ of the body weight at admission, ${ }^{18}$ which is consistent with the findings of the present study.

Conceivable reasons for reductions in body weight, SMI, and grip strength include surgical invasiveness, reduced dietary intake, and reduced activity during hospitalization. For 1 week after surgery, an increase in cytokines enhances catabolism, leading to a sudden reduction in lean mass. Body weight is still reduced at least 1 month after surgery due to a reduction in fat mass, which is attributed to reduced dietary intake. ${ }^{19,20}$ In oral cancer, surgery and chemoradiotherapy can easily result in dysphagia; ${ }^{21}$ the consequent reduction in dietary intake conceivably also affects reductions in body weight and SMI. Another conceivable factor for reduced body weight and SMI is reduced activity during hospitalization. ${ }^{22,23}$ Decreases in total protein ${ }^{24}$ and $\mathrm{BMI}^{25}$ have also been reported to lead to reduced grip strength. In the present study, we obtained similar results, which suggests that sufficient activity during hospitalization is important for patients at risk of reduced body weight and SMI after surgery.

High BMI and postoperative chemoradiotherapy were found to affect reductions in body weight and SMI. Elevated preoperative BMI and postoperative chemoradiotherapy are risk factors for reduced body weight at 6 months after cancer diagnosis. ${ }^{26}$ Another study also reported that postoperative radiotherapy is a risk factor for reduced body weight 1 year after surgery and that high preoperative BMI tends to be associated with body weight reduction. ${ }^{18}$ Male sex was also a risk factor for reduced SMI. Peng et al reported that men were more susceptible to reductions in muscle mass than women, ${ }^{24,27}$ which we observed in the present study.
In our study, only 1 patient had sarcopenia at admission, and 1 patient-developed sarcopenia during hospitalization; thus, we experienced very few cases of sarcopenia throughout the hospital stays. Awad et al have reported that in esophageal cancer, patients may lose lean mass and develop sarcopenia during preoperative chemotherapy, while patients who already have sarcopenia prior to preoperative chemotherapy experience major reduction in lean mass during chemotherapy. ${ }^{28}$ Other studies of head and neck cancer have reported high percentages of preoperative sarcopenia; however, these studies included patients with other cancers (oropharyngeal cancer, laryngeal cancer, etc.) and patients who had undergone chemoradiotherapy prior to surgery. ${ }^{9,10}$ The present study only included the oral cavity as the surgical site and excluded patients who had undergone chemoradiotherapy prior to surgery. This might explain the findings of minimal systemic effects and low prevalence of sarcopenia at admission. Preoperative BMI in the present study was $23.2(17.7-32.5) \mathrm{kg} / \mathrm{m}^{2}$, which was higher than the preoperative BMI of $22.0(13.9-34.8) \mathrm{kg} / \mathrm{m}^{2}$ in a previous study on gastrointestinal cancer. ${ }^{29}$ In the present study, sarcopenia was present at admission in 1 patient and the nutritional status of the other patients was relatively favorable. Therefore, it is possible that the reductions in body weight, SMI, and grip strength were not severe enough to lead to sarcopenia during hospitalization. These results suggest that patients with oral cancer who have a high BMI are susceptible to reductions in body weight and SMI, but not to the extent that leads to sarcopenia, and that sarcopenia does not develop during hospitalization in patients with oral cancer who do not require preoperative chemoradiotherapy.

In the present study, postoperative chemoradiotherapy was a risk factor for a low FOIS score at discharge, conceivably due to mucositis and dysphagia caused by chemoradiotherapy. Two patients developed mucositis during chemoradiotherapy, making it difficult for them to masticate food, so we changed their food to puree-like consistencies for a period.

Mekhail et al reported that acute reactions to chemoradiotherapy at 1 month included mucositis in $80 \%$ of patients and dysphagia in $90 \%$ of patients. ${ }^{30}$ Furthermore, dysphagia is more likely to occur after postoperative chemoradiotherapy than after only surgery. ${ }^{31}$ Based on the FOIS score, which is associated with the severity of dysphagia, $^{32}$ the present study yielded similar results. Mucositis and nausea associated with postoperative chemotherapy make oral intake difficult, and patients consume 
lower levels of a dysphagia diet or are tube-fed. Consequently, the FOIS score is reduced. Nutritional intervention has been reported to improve mucositis and is effective during postoperative treatment. ${ }^{33}$

In contrast, the reduced SMI was not a risk factor for a low FOIS score, possibly due to the low prevalence of sarcopenia during hospitalization in the present study. However, prolonged dysphagia after discharge sometimes results in reduced body weight and flap atrophy and would further exacerbate dysphagia. ${ }^{34}$ Therefore, in the future, it may be necessary to investigate post-discharge swallowing function and changes in body weight in patients with low FOIS scores at discharge and in patients who have undergone chemoradiotherapy prior to surgery.

In contrast to the large number of studies on preventing sarcopenia prior to surgery for gastrointestinal cancer, ${ }^{5-7}$ there are few studies on preventing sarcopenia prior to surgery for oral cancer. Consequently, the need for preoperative intervention is unknown. Motor rehabilitation prior to surgery for gastric cancer and lung cancer maintains and improves muscle mass. ${ }^{35,36}$ In the present study, because of the small number of patients with sarcopenia, we could not determine the need for preoperative nutritional intervention. We wish to conduct an additional study that includes patients who have undergone chemoradiotherapy prior to surgery to examine whether preoperative nutritional intervention is necessary for patients with oral cancer.

Limitations of the present study include the small sample size and single-center nature because of which we could not assess differences associated with surgical procedures. Because we excluded patients who had undergone chemoradiotherapy prior to surgery, we could not observe the effects of preoperative chemoradiotherapy. We also did not observe dietary intake or long-term postoperative progress. Furthermore, body composition was analyzed using a bioelectrical impedance analyzer, which cannot directly measure muscle mass. On the other hand, findings have shown computed tomography (CT) and magnetic resonance imaging (MRI) to be accurate for measuring human body composition. ${ }^{8,37}$ Therefore, continued research is necessary to address these limitations.

\section{Conclusion}

Patients who were hospitalized for resection and reconstruction for oral cancer and those who did not have prior chemoradiotherapy had significant reductions in body weight, muscle mass, and grip strength during hospitalization. However, none of these reductions were severe enough to lead to sarcopenia. Postoperative chemoradiotherapy was not only a risk factor for reduced body weight, reduced muscle mass, and dysphagia at discharge but also possibly a greater risk factor than surgical invasiveness. We believe that after surgery, in addition to follow-up for cancer, patients should also be followed up for assessing dysphagia, undernutrition, and sarcopenia.

\section{Acknowledgments}

This work was supported by JSPS KAKENHI grant number JP16K20689.

\section{Disclosure}

The authors report no conflicts of interest in this work.

\section{References}

1. Cruz-Jentoft AJ, Baeyens JP, Bauer JM, et al. Sarcopenia: European consensus on definition and diagnosis: report of the European Working Group on Sarcopenia in Older People. Age Ageing. 2010;39(4):412-423. doi:10.1093/ageing/afq034

2. Chen LK, Liu LK, Woo J, et al. Sarcopenia in Asia: consensus report of the Asian Working Group for Sarcopenia. J Am Med Dir Assoc. 2014;15(2):95-101. doi:10.1016/j.jamda.2013.11.025

3. Kehlet H, Mogensen T. Hospital stay of 2 days after open sigmoidectomy with a multimodal rehabilitation programme. $B r J$ Surg. 1999;86(2):227-230. doi:10.1046/j.1365-2168.1999.01023.x

4. Basse L, Hjort Jakobsen D, Billesbølle P, Werner M, Kehlet H. A clinical pathway to accelerate recovery after colonic resection. Ann Surg. 2000;232(1):51-57. doi:10.1097/00000658-200007000-00008

5. Ida S, Watanabe M, Yoshida N, et al. Sarcopenia is a predictor of postoperative respiratory complications in patients with esophageal cancer. Ann Surg Oncol. 2015;22(13):4432-4437. doi:10.1245/s10434015-4559-3

6. Lieffers JR, Bathe OF, Fassbender K, Winget M, Baracos VE. Sarcopenia is associated with postoperative infection and delayed recovery from colorectal cancer resection surgery. $\mathrm{Br} J$ Cancer. 2012;107(6):931-936. doi:10.1038/bjc.2012.350

7. Fukuda Y, Yamamoto K, Hirao M, et al. Sarcopenia is associated with severe postoperative complications in elderly gastric cancer patients undergoing gastrectomy. Gastric Cancer. 2016;19 (3):986-993. doi:10.1007/s10120-015-0546-4

8. Swartz JE, Pothen AJ, Wegner I, et al. Feasibility of using head and neck CT imaging to assess skeletal muscle mass in head and neck cancer patients. Oral Oncol. 2016;62:28-33. doi:10.1016/j.oraloncology.2016. 09.006

9. Tamaki A, Manzoor NF, Babajanian E, Ascha M, Rezaee R, Zender CA. Clinical significance of sarcopenia among patients with advanced oropharyngeal cancer. Otolaryngol Head Neck Surg. 2019;160(3):480-487. doi:10.1177/0194599818793857

10. Kabarriti R, Bontempo A, Romano M, et al. The impact of dietary regimen compliance on outcomes for HNSCC patients treated with radiation. Support Care Cancer. 2018;26(9):3307-3313. doi:10.1007/ s00520-018-4198-x

11. Suarez-Cunqueiro MM, Schramm A, Schoen R, et al. Speech and swallowing impairment after treatment for oral and oropharyngeal cancer. Arch Otolaryngol Head Neck Surg. 2008;134(12):1299-1304. doi:10.1001/archotol.134.12.1299

12. Dronkers JJ, Chorus AM, van Meeteren NL, Hopman-Rock M. The association of pre-operative physical fitness and physical activity with outcome after scheduled major abdominal surgery. Anaesthesia. 2013;68(1):67-73. doi:10.1111/anae.12066 
13. Onerup A, Bock D, Börjesson $\mathrm{M}$, et al. Is preoperative physical activity related to post-surgery recovery? - a cohort study of colorectal cancer patients. Int J Colorectal Dis. 2016;31(6):1131-1140. doi:10.1007/s00384-016-2551-4

14. Duffy AM, Halaki M, Spigelman A, Chin V, Gallagher RM, Flood VM. Nutritional parameters associated with hospital admissions in patients being treated for head and neck cancer. Support Care Cancer. 2019;5:1-9.

15. Wakabayashi H. Presbyphagia and sarcopenic dysphagia: association between aging, sarcopenia, and deglutition disorders. J Frailty Aging. 2014;3(2):97-103. doi:10.14283/jfa.2014.8

16. Azzolino D, Damanti S, Bertagnoli L, Lucchi T, Cesari M. Sarcopenia and swallowing disorders in older people. Aging Clin Exp Res. 2019;31(6):799-805. doi:10.1007/s40520-019-01128-3

17. Crowder SL, Douglas KG, Yanina Pepino M, Sarma KP, Arthur AE. Nutrition impact symptoms and associated outcomes in post-chemoradiotherapy head and neck cancer survivors: a systematic review. J Cancer Surviv. 2018;12(4):479-494. doi:10.1007/s11764-0180687-7

18. Suzuki M, Fujii T, Kurita T, et al. [Risk factors for body weight loss following reconstructive surgery for tongue cancer.]. Tokeibu Gan. 2015;41(1):30-34. doi:10.5981/jjhnc.41.30

19. Aoyama T, Kawabe T, Hirohito F, et al. Body composition analysis within 1 month after gastrectomy for gastric cancer. Gastric Cancer. 2016;19(2):645-650. doi:10.1007/s10120-015-0496-x

20. Abdiev S, Kodera Y, Fujiwara M, et al. Nutritional recovery after open and laparoscopic gastrectomies. Gastric Cancer. 2011;14 (2):144-149. doi:10.1007/s10120-011-0021-9

21. Raykher A, Russo L, Schattner M, Schwartz L, Scott B, Shike M. Enteral nutrition support of head and neck cancer patients. Nutr Clin Pract. 2007;22(1):68-73. doi:10.1177/011542650702200168

22. Coker RH, Hays NP, Williams RH, Wolfe RR, Evans WJ. Bed rest promotes reductions in walking speed, functional parameters, and aerobic fitness in older, healthy adults. J Gerontol Biol Sci Med Sci. 2015;70(1):91-96. doi:10.1093/gerona/glu123

23. Kortebein P, Ferrando A, Lombeida J, Wolfe R, Evans WJ. Effect of 10 days of bed rest on skeletal muscle in healthy older adults. JAMA. 2007;297(16):1772-1774. doi:10.1001/jama.297.16.1772-b

24. Peng S, Plank LD, McCall JL, Gillanders LK, McIlroy K, Gane EJ. Body composition, muscle function, and energy expenditure in patients with liver cirrhosis: a comprehensive study. Am J Clin Nutr. 2007;85(5):1257-1266. doi:10.1093/ajcn/85.5.1257

25. Pieterse S, Manandhar M, Ismail S. The association between nutritional status and handgrip strength in older Rwandan refugees. Eur J Clin Nutr. 2002;56(10):933-939. doi:10.1038/sj.ejen.1601443
26. Silander E, Nyman J, Hammerlid E. An exploration of factors predicting malnutrition in patients with advanced head and neck cancer. Laryngoscope. 2013;123(10):2428-2434. doi:10.1002/lary.23877

27. Yamada M, Moriguch Y, Mitani T, Aoyama T, Arai H. Agedependent changes in skeletal muscle mass and visceral fat area in Japanese adults from 40 to 79 years-of-age. Geriatr Gerontol Int. 2014;14(Suppl 1):8-14. doi:10.1111/ggi.12209

28. Awad S, Tan BH, Cui H, et al. Marked changes in body composition following neoadjuvant chemotherapy for oesophagogastric cancer. Clin Nutr. 2012;31(1):74-77. doi:10.1016/j.clnu.2011.08.008

29. Sato T, Aoyama T, Hayashi T, et al. Impact of preoperative hand grip strength on morbidity following gastric cancer surgery. Gastric Cancer. 2016;19(3):1008-1015. doi:10.1007/s10120-015-0554-4

30. Mekhail TM, Adelstein DJ, Rybicki LA, Larto MA, Saxton JP, Lavertu P. Enteral nutrition during the treatment of head and neck carcinoma: is a percutaneous endoscopic gastrostomy tube preferable to a nasogastric tube? Cancer. 2001;91(9):1785-1790. doi:10.1002/ (ISSN)1097-0142

31. Shin YS, Koh YW, Kim SH, et al. Radiotherapy deteriorates postoperative functional outcome after partial glossectomy with free flap reconstruction. J Oral Maxillofac Surg. 2012;70(1):216-220. doi:10.10 16/j.joms.2011.04.014

32. Crary MA, Mann GD, Groher ME. Initial psychometric assessment of a functional oral intake scale for dysphagia in stroke patients. Arch Phys Med Rehabil. 2005;86(8):1516-1520. doi:10.1016/j.apmr.2004.11.049

33. Takahashi M, Kosaka N, Wakui E, et al. Role of intensive nutrition support and prophylactic percutaneous endoscopic gastrostomy during concomitant chemoradiotherapy for oropharyngeal cancer. Int J Clin Oncol. 2018;23(6):1023-1028. doi:10.1007/s10147-018-1328-x

34. Hashida N, Shamoto H, Maeda K, Wakabayashi H, Suzuki M, Fujii T. Rehabilitation and nutritional support for sarcopenic dysphagia and tongue atrophy after glossectomy: a case report. Nutrition. 2017;35:128-131. doi:10.1016/j.nut.2016.11.003

35. Yamamoto K, Nagatsuma Y, Fukuda Y, et al. Effectiveness of a preoperative exercise and nutritional support program for elderly sarcopenic patients with gastric cancer. Gastric Cancer. 2017;20 (5):913-918. doi:10.1007/s10120-016-0683-4

36. Ni HJ, Pudasaini B, Yuan XT, Li HF, Shi L, Yuan P. Exercise training for patients pre- and postsurgically treated for non-small cell lung cancer: a systematic review and meta-analysis. Integr Cancer Ther. 2017;16:63-73. doi:10.1177/1534735416645180

37. Mitsiopoulos N, Baumgartner RN, Heymsfield SB, Lyons W, Gallagher D, Ross R. Cadaver validation of skeletal muscle measurement by magnetic resonance imaging and computerized tomography. J Appl Physiol. 1998;85(1):115-122. doi:10.1152/jappl.1998.85.1.115
Clinical Interventions in Aging

\section{Publish your work in this journal}

Clinical Interventions in Aging is an international, peer-reviewed journal focusing on evidence-based reports on the value or lack thereof of treatments intended to prevent or delay the onset of maladaptive correlates of aging in human beings. This journal is indexed on PubMed Central, MedLine, CAS, Scopus and the Elsevier
Bibliographic databases. The manuscript management system is completely online and includes a very quick and fair peer-review system, which is all easy to use. Visit http://www.dovepress.com/ testimonials.php to read real quotes from published authors. 